\title{
Sarbanes-Oxley and the Accounting Profession: Public Interest Implications
}

\author{
Sara Ann Reiter ${ }^{1}$, Paul F. Williams ${ }^{2}$ \\ ${ }^{1}$ Binghamton University, Binghamton, USA \\ ${ }^{2}$ North Carolina State University, Raleigh, USA \\ Email: sreiter@binghamton.edu
}

Received October 31, 2012; revised December 1, 2012; accepted December 12, 2012

\begin{abstract}
The US accounting profession was caught up in, and some say responsible for, the whirlwind of accounting and business scandals that rocked the US markets in 2002. To restore investor confidence in financial information, the Sarbanes-Oxley Act created a new Public Company Accounting Oversight Board with the authority to set standards for auditors of publicly traded companies, thus ending a century of professional regulation of auditing. In this analysis we employ sociological theories of professionalism [1-4] to help understand the implications of the Sarbanes-Oxley legislation for the accounting profession and for the public interest. We explain why professional self-regulation is important for retaining valuable economic franchises. We also explain why the public interest orientation of the profession is important and how government take-over of auditing standards potentially erodes the public accounting profession's commitment to the public interest. Self-control over professional work, a key characteristic of professional status, is pre-empted by the newly created government oversight body PCAOB. With government takeover of oversight of auditing practice, claims to professional status are weakened and professional commitment to and involvement with vital work standards may suffer. In addition, the profession may no longer have incentives to promote the public interest or to innovate and change in response to changing conditions. We also trace events leading up to Sarbanes-Oxley legislation and conclude that underlying problems arising from internal work differentiation as consulting work became more profitable and glamorous and development of a commercially oriented work culture may continue to threaten the profession in the future. Finally, we speculate that the greatest costs may be opportunity costs as the profession no longer has the incentives or ability to innovate and embrace new forms of accountability.
\end{abstract}

Keywords: Accounting Profession; Sarbanes-Oxley; Public Interest

\section{Introduction}

The US accounting profession was caught up in, and some say responsible for, the whirlwind of accounting and business scandals that rocked the US markets in 2002. To restore investor confidence in financial information, the Sarbanes-Oxley Act created a new Public Company Accounting Oversight Board with the authority to set standards for auditors of publicly traded companies, thus ending a century of professional regulation of auditing.

We conclude that this change results in a significant decrease in the professional status of auditors which also affects other groups in the broader accounting profession. The professional status of auditors is important in retaining the monopoly over audit work that is at the economic core of the profession. Control of professional work, lost to government regulators under Sarbanes-Oxley, is necessary for development and adaptation of the professsional skills upon which the government monopoly relies.
In addition, the decline of professional control over auditing work has potential negative effects on the public interest because it undercuts the profession's need to maintain a public interest ideology.

The first section of the paper provides the basis for these conclusions. In the second section of the paper, we examine factors leading to the crisis of confidence resulting in the Sarbanes-Oxley legislation and conclude the many of these problems, such as internal differentiation and loss of professional character, remain unresolved.

\section{Sarbanes-Oxley and the Accounting Profession}

First we need to establish why professional status is important to accountants and why a decline in professional status should be a concern. We rely on critical sociological theory [1-4] in our analysis of the meaning of professsional status. Willmott [5] distinguishes critical so- 
ciological theory from its predecessor functionalist and interactionist forms by noting that "the functionalist perspective usefully highlights the significance of traits of professionalism in relationship to the reproduction of complex social systems", while the "interactionist perspective helpfully recalls the socially constructed nature of these traits, setting them in the context of a negotiated interaction over the symbolic meaning and value of 'professional' expertise. Finally, the critical approach deepens the insights of the interactionist approach by placing them in the wider economic and political context” [5, p. 559].

Some critical theorists view the professional project in essentially economic terms. Larson contends that "Professionalism is thus an attempt to translate one order of scarce resources-special knowledge and skills-into another-social and economic rewards" [6, p. 17]. Other theorists, like Freidson [1-3] contend that there is more to the professional project than attaining economic monopolies, asserting that the "institutions of professionalism are grounded not only in an economy but also in a social enterprise of learning, advancing, and practicing a body of specialized knowledge and skill” [3, p. 198]. In other words, he believes that professionals provide essential services and part of the analysis of the professional project has to take the potential public interest served into account. Finally, ideology is of great importance to the professional project $[3,4]$. A professional ideology reinforcing an important public interest function is critical to maintain internal cohesion and to maintain the important public perception that the profession is vital to the public interest, a perception that results in the government awarding service monopolies to the profession.

In summary, professions are seen in terms of their economic monopolies, their professional work and skills, and their ideologies. Following these three lines of thought, we trace the potential economic effects of a decline in professional status, the potential effects of loss of professional control over auditing practices and standards, and the likely public interest effects from changes in professional ideology. The work of two particular sociological theorists forms the framework for this analysis. Abbott [4] theorizes professions as groups with jurisdiction over professional tasks-a jurisdiction that is based in economics, negotiated with other groups, and in a constant state of change. Freidson [1-3] bases his analyses on the characteristics of an ideal profession with emphasis on understanding the key interactions between those characteristics. The characteristics are seen not so much as traits but as functional building blocks for professions. For example, professional control over practitioner qualifications is important for maintaining professsional control of work.

\subsection{What Is the Accounting Profession?}

While some see the public accounting (auditing) profession as distinct from other accounting professions, such as education, private enterprise, not-for-profit and governmental [7], we define the accounting profession more broadly and see the various segments as internal differentiation within a profession. Histories of the early days of the accounting profession in various countries detail struggles to define which occupational groups would and would not be included in the profession associations $[5,8,9]$. In the U.S. the premier event leading to professional status for accountants was the franchise given to public accountants by the securities legislation of the 1930s [10]. This legislation both requires publicly traded companies to purchase independent audits of their financial statements and defines public accountants as the sole providers of such audits. The professional status of accounting is therefore dependent on the public wing of the profession, however even the American Institute of Certified Public Accountants has only a minority of its members currently in public practice. Both in the UK and the US the profession is fragmentary with many subspecializations. Roslender [11] notes that aside from auditing, the accounting profession is not exclusive and does not depend on a government supported monopoly. One does not have to be a CPA to provide taxation, statement preparation, and other services.

Abbott [4] and Freidson [3] explain that once a profession has achieved professional status, they then begin to bring various related functions under the umbrella of that professional distinction. So, for example, accountants in the US have provided taxation and information services as an adjunct to audit practice and these activities are clothed in the ideological mantle of the profession for a marketing advantage when supplied by CPAs —although both services can be bought as well from non-accountants. This is precisely the type of situation theorized by Abbott [4] where a number of related functions rely on the professional status of the core function in competition for professional jurisdiction or work. This type of internal differentiation can result in considerable tensions with the profession, as explained in the second section of this paper.

Our analysis of the effects of Sarbanes-Oxley legislation on the accounting profession focuses on the core activity of public accounting or auditing. Other segments of the accounting profession not involved in auditing publicly traded companies are affected indirectly by Sarbanes-Oxley legistation, but all of the segments of the profession will suffer some decline if the core of the profession, pubic accounting, is threatened.

\subsection{Sarbanes-Oxley Legislation}

In 2001 and 2002, a series of accounting scandals were 
uncovered at major corporations. At the same time, the market bubble burst sending stock prices and investor confidence plummeting. The role of auditors in these scandals led to a deepening concern with the effectiveness of professional self-regulation.

High-profile business failures culminating in a media fixation of Enron called into question the effectiveness of the profession's self-regulatory process as well as the effectiveness of the audit to uphold the public trust in the capital markets. Legislation to address shortcomings in financial reporting was progressing in Congress and the sudden revelation and collapse of WorldCom guaranteed swift congressional action. President Bush on July 30 signed into law the Sarbanes-Oxley Act of 2002, the most significant legislation affecting the accounting profession since 1933 [12].

Provisions of the new law affecting auditor independence include the creation of a Public Company Accounting Oversight Board to set auditing and quality control standards, including independence, for auditors of public companies. In addition, the act calls for rotation and review of lead audit partners and restricts consulting work that auditors can perform for publicly traded audit clients [12]. Carmichael explains that the new regulatory body, the PCAOB, is an independent private sector body overseen by the SEC which has powers to register public accounting firms, conduct inspections of auditing practices, enforce compliance with professional standards and securities laws, discipline firms or persons, and establish audit, ethics and independence standards [13, pp. 127128]. Carmichael notes that the Sarbanes-Oxley Act "removed from auditors the ability to exclusively interpret their role in society" [13, p. 130]. In fact, when the PCAOB adopted the auditing and professional standards that had been developed for many years by the AICPA, and that decision was approved by the SEC, the auditing standards became federal law rather than a set of professional practices.

\subsection{Key Aspects of Professionalism}

Public accountancy, is generally viewed as a profession both by academics and the public. Freidson [3] notes five interdependent elements of the ideal type professionalism:

1) Specialized work in the officially recognized economy that is believed to be grounded in a body of theoretically based, discretionary knowledge and skill and that is according given special status in the labor force;

2) Exclusive jurisdiction in a particular division of labor created and controlled by occupational negotiation;

3) A sheltered position in both external and internal labor markets that is based on qualifying credentials created by the occupation;

4) A formal training program lying outside the labor market that produces qualifying credentials, which is controlled by the occupation and associated with higher education; and

5) An ideology that asserts greater commitment to doing good work than to economic gain and to the quality rather than the economic efficiency of the work [3, p. 127].

These elements are interdependent-for example, professions maintain exclusive jurisdiction, in part, by promoting their ability to perform specialized work.

The three key elements of professions are the existence of a "labor market shelter" by which the profession is shielded from competition, retention of professional control (as opposed to client or state control) over judging and evaluating professional work, and maintenance of a public interest ideology [3].

A labor market shelter represents "occupational control over supply and the substance of demand" for particular work and effective formally negotiated labor market shelters are always based on some public claim of specialized training and skill that secures a state sanction for an exclusive right to supply certain kinds of labor [2, pp. 82-83]. As Freidson [2, p. 173] explains, "an occupation can fend off control by individual or corporate consumers of their work only by having power delegated to it by the state." He explains that "Ideal-typical professionalism is always dependent on the direct support of the state and some degree of tolerance of its position by both consumers and managers" [3, p. 122]. The statutory requirement for audits by certified public accountants for publicly listed firms is an example of a state supported labor market shelter. If the state did not require audits for publicly traded corporations and did not require that audits be performed by a certain set of people as defined by the public accounting profession, it would be very difficult for the auditing profession to maintain their market share in face of true competition. However, this requires the profession to convince the State that only they have the skills, training, and commitment to provide these essential services, and that they accept an obligation to act in the underlying public interest even while pursuing their own profit motives.

Another key characteristic of professionals is that they have technical autonomy and some degree of discretion in performing work that must be conducted in accordance with a personal, schooled judgment [1, p. 141]. Even though professional work is often employed within bureaucratic setting and control, supervision of the professional work and judgment of its quality is the purview of skilled professionals. For example, in accounting it is the peer review process, not the opinion of the client, that determines the quality of an audit. Freedom from the authority of others over their work is one of the defining characteristics of professions [2, p. 115] and one that has been lost by the US auditing profession with the current 
change to government regulation of audit standards and practices.

Finally, professionals have a motivation to present a public interest ideology. The ideology is important for getting and maintaining a public perception of the skills and commitment of the profession that results in eventual State sponsorship of a labor market shelter [3,4]. It is important to note that neither Abbott nor Freidson take the ideological commitment of the profession at face value. It is important for the profession to convince key constituencies of its ideological commitment and the importance of that commitment to a meaningful public goal. It is important to maintain that belief at some level. This does not imply that the profession or its members actually adhere strongly to, or behave according to, the ideology. This is why scandals, which reveal the gap between the ideology and reality, can be potentially so damaging to the profession.

\subsection{Implications of Sarbanes-Oxley}

Why is this decline in the professional control of auditors over their "labor market shelter" and over the judgment of professional work a problem for the profession, and why might it result in a decline in the profession's public interest ideology? The changes resulting from the Sarbanes-Oxley act subject the auditing profession to increased government oversight through the PCAOB takeover of setting audit standards, conducting peer reviews, and disciplining professional practice associated with public securities offerings. This represents a serious threat to the professional status of auditors because freedom from the authority of others over their work is one of the defining characteristics of professions [2, p. 115]. This control is central to the sustaining belief that professional actions are valuable and form the basis for a labor market shelter or government sponsored service monopoly. If outsiders can understand the nuances of professional judgment well enough to design work controls or to evaluate professional actions, then what special claims does the profession have to the work, and why should the profession receive valuable state support for its monopoly status? Why not have government auditors rather than private sector auditors under government control?

There are other implications of bureaucratic control of auditing for the public interest. There is a strong public interest in the integrity of the auditing profession. As former SEC Chief Accountant Lynn Turner reiterates, "the enduring confidence of the investing public in our capital markets is vital... [and] public trust begins, and ends, with the integrity of the numbers the public uses to form the basis for making investment decisions" [14]. Accountant's key position as "gatekeepers" to the public securities markets has been supported by the SEC, and "Congress, in creating a system in which investors and the Commission must rely on the accounting profession, granted the accounting profession an important public trust” [15]. SEC Commissioner Isaac Hunt goes on to note that Congress had other alternatives to relying on the integrity and self-governing ability of the accounting profession in setting up the system of the US public securities markets. The implication is that the accounting profession should be mindful of its obligation to serve the public interest in order to protect the franchise which forms the core of its professional status. As Lynn Turner [16] notes in his last speech as Chief Accountant:

A recent commentary in Business Week stated that auditor's reports today have about as much credibility as analysts' reports. I take great exception to that statement. But what I think and what you think doesn't really matter in the court of public opinion. What matters are what the public thinks, and its confidence in the credibility of our work.

Yet the level of restatements, massive financial frauds, and concerns with the quality of the numbers being reported in the press will erode that confidence if allowed to continue. Even people in the profession are asking why are we more focused on branding a consulting image such as XYZ or Cognitor rather than the internationally recognized name of CPA?

What direction should be taken, however, if the public ceases to believe in CPAs? In other words, is it in the public interest to have professions serving important public interest functions or should they be served by government regulation or by market forces? The profession's claims that market forces supply the motive to maintain effective self regulation and independence currently ring a bit hollow [17-19]. However, is government regulation a good alternative?

For one thing, even though government regulators may have the means and will to enforce changes resisted by public accounting in the wake of a massive set of scandals, this ability and will may not persist over time. We can observe the great power of industry lobbying to affect government's will to regulate in the events leading to the resignation of SEC Chair Harvey Pitt and the watering down of SEC regulations affecting the audit profession [20]. In the absence of pressure from immediate scandals, government cannot be trusted to uphold standards. In an ideal world, the professions should demonstrate their public interest commitments and organize effective self-regulation mechanisms because they have the most effective and sustained motivation to do so. Even in a less than ideal world, it is not clear that government or bureaucratic regulation is a good long-term alternative when market or economic regulation appear to fall short. 
While the government backed PCAOB may currently be serving to strengthen the hands of auditors in their negotiations with corporate clients, history suggests that lobbying efforts have often been effective in blunting the powers of government regulators. Meanwhile, the accounting profession is always looking for advantage and a recent meeting of the American Assembly [21] found ways to potentially turn PCAOB regulation to the advantage of the profession. They saw, for example, an opportunity to educate the public about the inexactitude of financial statement numbers and match attestation opinions to the nature of information the auditor is expected to attest. They hypothesized that the PCAOB might be able to examine audit processes and provide some sorts of safe harbor for application of principles requiring judgment and for auditing the results of high risk clients. This seems to be a continuation of the decades long expectations gap where the response of the profession to the public's high expectations from auditing financial statements is that the public should be re-educated to have greatly reduced expectations. The position of Douglas Carmichael [13], Chief Auditor of the PCAOB, that the standards for audits need to be set precisely to meet the expectations of users is in direct conflict with the profession's desire to limit responsibility.

As for the ideological commitment of the accounting profession, a number of authors detail its erosion over the latter half of the 20th century in favor of a commercial orientation (see for example, Bailey [22] and Wyatt [23]). The passage of the Sarbanes-Oxley legislation signals a significant loss of confidence by the state in the public interest commitment of the accounting profession. Another possible result of the PCAOB takeover of oversight of auditing standards and practice is that the profession might withdraw from concern with maintaining a public interest commitment. Zeff $[24,25]$ reports declining audit firm involvement with accounting standards after standard-setting shifted to the private sector FASB. Freidson's concerns with the importance of professional selfregulation relate to the necessity for continued professional commitment to and involvement with their own specialized body of knowledge and skills. If auditors come to disagree with or resist the standards imposed upon them, presumably professional practice will suffer, and professional ideology will decline.

\section{Underlying Issues in the Accounting Profession}

While the Sarbanes-Oxley legislation was a response to a particular set of market scandals, a number of unresolved issues had been developing surrounding public accounttancy for years. If these underlying problems remain unresolved, they will continue to affect the ability and will- ingness of the accounting profession to meets its public interest obligations.

\subsection{A Brief History}

Several recent accounts trace the factors that led to the failure of profession to retain its full professional status. Zeff [24] places the pinnacle of status of the US accounting profession in the 1940s to mid 1960s. However, the subsequent movement of the profession into information-based services triggered an internal differentiation that would ultimately erode the public interest ideology of the profession [23]. As the markets gained increased prominence and importance in the 1960s, activities surrounding the markets became more visible. The late 1960s ushered in an era of "scandals, lawsuits, and criticism of the profession" [24, p. 196]. In the 1970s accounting standard setting passed from the profession to a private standard-setting body and Zeff notes a decline in interest by the profession in taking public positions on accounting standards. Congressional hearings in the late 1970s resulted in the first of a series of reforms in the self-regulation process of the profession. In addition, growth of controversial management advisory services continued despite the concern of regulators. Zeff [25] notes a deterioration of professional values and professional climate in the 1980s on due to increases in the competitive environment. Economic pressures in turn led to an increasing move into provision of consulting services and changes in expectations of partners from delivering high quality audit services to bringing in revenue growth.

The profession responded weakly to the Savings and Loan crisis, other scandals and additional congressional hearings. Pressure from clients for favorable accounting treatments that showed continual growth also escalated in the 1980s and 1990s. While the SEC and others increase Zeff [25] concludes that the auditors themselves became even less involved with professional issues or identification, focusing more on growth of their consulting businesses. Zeff notes that the concerns of regulators were opposed or ignored by audit firms and the work climate and business model of accounting practice became even more oriented toward consulting work.

\subsection{Economic Differentiation}

Wyatt [23] provides in insider's view of the change from a professional and firm culture based on ethics to the primacy of consulting practice and business concerns. Factors identified with the decrease in professionalism include an increased tendency to hire non-accounting graduates such as information specialists, the pressure created by the success of consulting practice for increased profitability in the audit practice, and the rise of 
internal firm cultures based on growing revenues and profitability.

In sociological theories of professions [3,4,6], economic interests are at the core of the professional project. When the perceived economic value of a peripheral activity, such as information technology consulting, begins to surpass the perceived economic value of the profession's core monopoly activity (auditing), problems are bound to result. The motivation of the profession to protect the value of its core product is diminished. In the case of auditing there are further problems because pursuit of the peripheral activity arguably has implications for the ability of the auditor to maintain a vestigal degree of independence from the client. If the business model is such that required audits are seen as platforms to compete effectively for lucrative consulting business, then auditors may not be in a position to interpret accounting and auditing standards in a fair and objective. There was considerable debate about whether there was empirical evidence that independence had been impaired by client pressure, however there can be no doubt that the business model of using audit work as a platform for selling other services embodied serious conflicts of interest.

The "fall of the accounting profession" can be seen as a situation where perverse economic incentives associated with the consulting culture overwhelmed positive economic incentives to preserve the integrity of audits [6] or as a situation where internal differentiation of the profession resulting from the precipitous rise of information services/consulting played havoc with the ability of the profession to remain committed to its core business of auditing [4]. For either of these two explanations, the solution is to revitalize the economic incentives associated with auditing - and ironically the internal control certification requirements associated with Section 404 of the Sarbanes-Oxley act appear to have just that effect. Douglas Carmichael, Chief Auditor of the PCAOB, presents the goal of the auditing profession in economic terms. He relies on the theory of inspired confidence, an economic theory wherein the goal of auditing is to meet society's needs and states that auditing standards will be set with a goal to "perform enough work to meet the expectations the auditor has aroused in society" [13, p. 129].

In the short term Sarbanes-Oxley provisions, particularly in relation to internal control requirements, may have the effect of revitalizing the economic value of audit practice. Furthermore, Sarbanes-Oxley legislation severely restricts the ability of firms to provide consulting services to audit clients, therefore changing the business model that has dominated accounting practice. However, in the long term, economic conflicts between the value of auditing and consulting are bound to re-appear. The internal differentiation of the profession will continue to pose problems for the profession. While the public accounting profession, particularly the large firm segment engaged in audits of publicly traded companies, is directly affected by Sarbanes-Oxley, other segments of the accounting profession are affected as well. Abbott [4] explains that the different segments of professions and the other work groups with whom they compete are all inter-related. Abbott's "system of professions" is always in flux, with different work groups competing for jurisdiction.

\subsection{Professional Character}

Zeff $[24,25]$ and Wyatt [23] ascribe the decline of the accounting profession to a turning away from the central ethical commitment of professionalism. This situation is not unique to accounting. Wolfe [26] asserts that there has been a change in the moral sensibility of American society from reifying moral or character-based traits to admiring economic traits. Reiter and Williams [27] explain how the narratives of legitimation of the profession have changed over the years from emphasis on the professional character on accountants to emphasis on the judicial neutrality of accountants to promotion of accountants as economic characters upholding audit independence because it serves their self-interest.

While the SEC and the government seek to restore public confidence in CPAs and audited financial statements by taking over regulation of auditing standards and practices and enhancing the role of corporate governance, particularly audit committees, in overseeing the actions of management, the accounting profession is seeking to re-establish trust in CPAs. Melancon [28] calls for a return to a culture built "upon the profession's traditional values". PWC [29] exhorts auditors to rebuild trust through rededication to core values such as integrity, re-activation of professional judgment, and adoption of clear codes of conduct and corporate cultures emphasizing integrity. Likewise Wyatt [23] sees the redemption of CPAs in the reestablishment of professional character.

However, sociological theory would prompt us to ask whether professionalism is really about character, or always about economic interests. Freidson [2, p. 124] explains that "the notions of dedication to service and of craftsmanship are more usefully treated as elements of an ideology than as empirical characteristics of individual and collective professional behavior". Also, one should expect that economic interests and professional ideology will always be in conflict. As Larson [6] notes, “.... at the core of the professional project, we find the fusion of antithetical ideological structures and a potential for permanent tension between 'civilizing function' and market orientation, between the 'protection of society' and the serving of a market...” (p. 63). Therefore, recent professional commitments to re-establish the character of pub- 
lic accountants may have more to do with strengthening others' beliefs in the ideology of the accounting profession than with a profound change in the underlying economic values of the profession.

Furthermore, the profession may find it difficult to develop or change character. Character is based on actions and the internal culture of the profession is formed through actions. If the criteria for reward and promotion for years have been based on salesmanship or commercial values, how easy is it to switch to a culture based on ethical values?

\section{Conclusions}

The interactionist theories of sociologists Abbott [4] and Freidson [3] provide a framework for speculating about the public interest implications of the Sarbanes-Oxley act, particularly for the public accounting segment of the accounting profession. The loss of control over professional work has serious implications for the maintenance of the profession's economic monopoly and for the profession's motivation to promote a professional ideology. Problems arising from the changing economic incentives to compete for the various forms of professional work will continue to haunt the profession as long as consulting services are perceived as more lucrative than auditing. It may not be easy to change the culture of the profession from a commercial culture back to a culture based on professional ideology.

However, some of the most damaging implications may come from missed opportunity costs. Sarbanes-Oxley legislation has the potential to freeze public accountants into a certain role, that of policing corporations. Auditors are to be the internal eyes and ears for persons outside the corporation to be able to hold these massive entities accountable. But for what, and in what ways should corporations be accountable to the public and how can the public accounting profession adapt to changing roles and expectations when its regulatory functions have been co-opted by government bureaucracy?

\section{REFERENCES}

[1] E. Freidson, "Professional Powers: A Study of the Institutionalization of Formal Knowledge," The University of Chicago Press, Chicago, 1986.

[2] E. Friedson, "Professionalism Reborn: Theory, Prophecy and Policy,” The University of Chicago Press, Chicago, 1994.

[3] E. Friedson, "Professionalism: The Third Choice," The University of Chicago Press, Chicago, 2001.

[4] A. Abbott, "The Systems of Professions," The University of Chicago Press, Chicago, 1988.

[5] H. Willmott, "Organising the Profession: A Theoretical and Historical Examination of the Development of the
Major Accountancy Bodies in the UK," Accounting, Organizations and Society, Vol. 11, No. 6, 1986, pp. 555580. doi:10.1016/0361-3682(86)90036-X

[6] M. S. Larson, "The Rise of Professionalism: A Sociological Analysis,” The University of California Press, Berkely and Los Angeles, 1977.

[7] H. Hendrickson, "Some Comments on the Impact of the Economic Power Exercised by the AICPA and the Major Accounting Firms," Critical Perspectives on Accounting, Vol. 12, No. 2, 2001, pp. 159-166. doi:10.1006/cpac.2001.0461

[8] T. Lee, "The Professionalization of Accountancy: A History of Protecting the Public Interest in a Self-Interested Way," Accounting, Auditing \& Accountability Journal, Vol. 8, No. 4, 1995, pp. 48-69. doi:10.1108/09513579510100725

[9] W. F. Chua and C. Poullaos, "The Dynamics of 'Closure' Amidst the Construction of Market, Profession, Empire and Nationhood: An Historial Analysis of an Australian Accounting Association 1886-1903,” Accounting, Organizations and Society, Vol. 25, No. 2, 1998, pp. 155-187. doi:10.1016/S0361-3682(97)00009-3

[10] B. D. Merino and A. G. Mayper, "Securities Legislation and the Accounting Profession in the 1930s: The Rhetoric and Reality of the American Dream," Critical Perspectives on Accounting, Vol. 12, No. 4, 2001, pp. 501-525. doi:10.1006/cpac.2000.0432

[11] R. Roslender, "Sociological Perspectives on Modern Accountancy,” Routledge, London, 1992.

[12] American Institute of Certified Public Accountants, "Landmark Accounting Reform Legislation Signed Into Law," The CPA Letter, AICPA, New York, 2002.

[13] D. R. Carmichael, "The PCAOB and the Social Responsibility of the Independent Auditor," Accounting Horizons, Vol. 18, No. 2, 2004, pp. 127-133. doi:10.2308/acch.2004.18.2.127

[14] L. E. Turner, "Independence: A Covenant for the Ages," Speech by SEC Staff, 2001. http://www.sec.gov/news/speech/spch504.htm

[15] I. C. Hunt Jr., "Accountants as Gatekeepers-Adding Security and Value to the Financial Reporting System," Speech by SEC Staff, 2001. http://www.sec.gov/news/speech/spch518.htm

[16] L. E. Turner, “We’re Good but We Can Be Better,” Speech by SEC Staff, 2001. http://www.sec.gov/news/speech/spch511.htm

[17] R. K. Elliott and P. D. Jacobson, "SEC Independence Concepts,” The CPA Journal, Vol. LXVIII, No. 4, 1998, pp. 14-20.

[18] R. K. Elliott and P. D. Jacobson, “Audit Independence Concepts,” The CPA Journal, Vol. LXVIII, No. 12, 1998, pp. 30-34, 36, 37.

[19] W. R. Kinney, “Auditor Independence: A Burdensome Constraint or Core Value?” Accounting Horizons, Vol. 13, No. 1, 1999, pp. 69-75. doi:10.2308/acch.1999.13.1.69

[20] S. Labaton, "S.E.C.'s Embattled Chief Resigns in Wake of Latest Political Storm,” The New York Times, 6 No- 
vember, 2002.

[21] American Assembly, "The Future of the Accounting Profession,” The American Assembly, Columbia University, New York, 2003.

[22] A. B. Bailey, “The Practicing Professional’s Mental Model: Are We Creating the Right Mental Models for New Professionals?” Issues in Accounting Education, Vol. 10, No. 1, 1995, pp. 191-195.

[23] A. R. Wyatt, “Accounting Professionalism-They Just Don't Get It!” Accounting Horizons, Vol. 18, No. 1, 2004, pp. 45-53. doi:10.2308/acch.2004.18.1.45

[24] S. A. Zeff, "How the US Accounting Profession Got Where It Is Today: Part I,” Accounting Horizons, Vol. 17, No. 3, 2003, pp. 189-205. doi:10.2308/acch.2003.17.3.189
[25] S. A. Zeff, "How the US Accounting Profession Got Where It Is Today: Part II,” Accounting Horizons, Vol. 17, No. 4, 2003, pp. 267-286. doi:10.2308/acch.2003.17.4.267

[26] A. Wolfe, "Whose Keeper? Social Science and Moral Obligation,” The University of California Press, Berkely, 1989.

[27] S. A. Reiter and P. F. Williams, "The Philosophy and Rhetoric of Auditor Independence Concepts,” Business Ethics Quarterly, Vol. 14, No. 3, 2004, pp. 355-376. doi:10.5840/beq200414329

[28] B. C. Melancon, “A New Accounting Culture,” Yale Club, New York, 2002.

[29] PricewaterhouseCoopers, "Stand and Be Counted," PricewaterhouseCoopers, London, 2003. 